Published in final edited form as:

Surg Clin North Am. 2011 April ; 91(2): 403-ix. doi:10.1016/j.suc.2010.12.003.

\title{
Palliative Care in Lung Cancer
}

Betty Ferrell, PhD, FAAN, MA, FPCN ${ }^{\mathrm{a}}$, Marianna Koczywas, MD $^{\mathrm{b}}$, Fred Grannis, MD $^{\mathrm{c}}$, and Annie Harrington, MD $^{\mathrm{d}}$

aProfessor and Research Scientist, Nursing Research \& Education, Department of Population Sciences, City of Hope, Duarte, CA

${ }^{b}$ Associate Professor of Medicine, Division of Medical Oncology and Therapeutics Research, Thoracic Oncology and Lung Cancer Program, City of Hope, Duarte, CA

${ }^{\circ}$ Clinical Professor, Department of Surgery, Thoracic Surgeon, Thoracic Cancer Program, City of Hope, Duarte, CA

dFellow, Pulmonary-Critical Care, Cedars Sinai Medical Center, Los Angeles, CA This work is supported by Grant No. P01-CA136396-01 from the National Cancer Institute

\section{Keywords}

palliative care; quality of life; symptom management

\section{Introduction}

An estimated 222,000 new cases of lung cancer will be diagnosed in the United States in 2010, and approximately 157,000 patients will die from the disease (1). Despite complete resection and curative intent, many patients with early stage, resectable lung cancer will experience recurrence. Following potentially curative surgical resection, the five-year survival rate for early stage NSCLC is commonly accepted to be 60 to $80 \%$ for stage I, 40 to $50 \%$ for stage II, and 10 to $20 \%$ for stage IIIA $(2,3)$. Two thirds of these patients will recur systemically, and the remaining one third will recur locally (4). Since recurrent disease is common, aggressive symptom management and support utilizing an interdisciplinary palliative care model becomes an important aspect of care. This paper aims to describe the role of palliative care for patients with lung cancer.

\section{Defining Palliative Care}

Palliative care is a concept in medical care that has expanded within the last decade to address the supportive care needs that accompany the occurrence of life-threatening disease.

\footnotetext{
(c) 2010 Elsevier Inc. All rights reserved.

${ }^{\mathrm{a}}$ Corresponding author for proof and reprints: Betty Ferrell, PhD, MA, FAAN, FPCN, City of Hope, Duarte, CA 91010, (626) 256-4673 x62825, (626) 301-8941 fax, bferrell@coh.org.

b,c,d Coauthor's addresses: Marianna Koczywas, MD, City of Hope, 1500 E. Duarte Rd., Duarte, CA 91010, (626) 256-4673, (626) 256-5461 fax, mkoczywas@coh.org

Fred Grannis, MD, City of Hope, 1500 East Duarte Road, Duarte, CA 91010, 626-471-7100, 626-471-7215 fax, fgrannis@coh.org Annie Harrington, MD, Cedars Sinai Medical Center, 8700 Beverly Blvd., Room 6732, Los Angeles, CA 90048, 310-432-1835, 310-423-0129 fax, annie.harrington@cshc.org

The authors have nothing to disclose

Publisher's Disclaimer: This is a PDF file of an unedited manuscript that has been accepted for publication. As a service to our customers we are providing this early version of the manuscript. The manuscript will undergo copyediting, typesetting, and review of the resulting proof before it is published in its final citable form. Please note that during the production process errors may be discovered which could affect the content, and all legal disclaimers that apply to the journal pertain.
} 
The concept addresses different aspects in the trajectory of cancer. In its recent 2009 update, the National Consensus Project (NCP) Clinical Practice Guidelines for Quality Palliative Care defines palliative care as "medical care provided by an interdisciplinary team, including the professions of medicine, nursing, social work, chaplaincy, counseling, nursing assistant, and other health care professions focused on the relief of suffering and support for the best possible quality of life for patients facing serious life-threatening illness and their families. It aims to identify and address the physical, psychological, spiritual, and practical burdens of illness."(5) Figure 1 illustrates how palliative care fits with the treatment of lung cancer. Palliative care begins at the time of diagnosis of a serious disease, continues throughout treatment, cure, or until death, and involves the family during the bereavement period.

Studies have been conducted during the past few decades to determine the effect of early introduction of palliative care in cancer. Recently, Temel and colleagues published findings from a randomized clinical trial to examine the effect of introducing palliative care at diagnosis on quality of life (QOL) changes at 12 weeks for patients with metastatic nonsmall-cell lung cancer. Patients enrolled in the study received either early palliative integrated with standard oncologic care or standard oncologic care alone $(\mathrm{n}=151)$. (6) Results were in favor of the early palliative care group, where better QOL was observed compared with patients who received standard oncologic care only. Fewer depressive symptoms were observed for the palliative care group. Most interestingly, patients in the palliative care group received less aggressive care at the end of life, but their median survival was longer (11.6 months vs. 8.9 months, $\mathrm{p}=0.02$ ). (6)

\section{Quality of Life (QOL) and Symptoms in Early Stage NSCLC}

Several studies have described QOL in early stage NSCLC post-operatively. Balducyk and colleagues followed 100 NSCLC patients for 12 months post-operatively and found that the QOL evolution in patients who received a lobectomy or wedge resection was comparable, with a 1-month transient decrease in functioning and increase in pain (7). Other studies have found similar transient QOL decreases postoperatively, with general recovery seen between 3-9 months postoperatively $(8,9)$. Patients who underwent a pneumonectomy had the worst outcome, with poor physical functioning, role functioning, pain, dyspnea, emotional problems, and decreased pulmonary functions that did not recover to baseline (10). Pneumonectomy was also found to be predictive for hospital readmissions and mortality postoperatively (11).

In a longitudinal study exploring QOL in patients with resected NSCLC two years postoperatively, surgery substantially reduced QOL across all dimensions except emotional functioning (4). Approximately half of patients continued to experience symptoms and diminished functioning after two years (12). In a study with long-term survivors of lung cancer ( $>5$ years), Sarna and colleagues found that $22 \%$ of survivors had distressed mood, and $50 \%$ experienced moderate to severe pulmonary distress (13).

Studies have also identified determinants of QOL following pulmonary resections. Preoperative QOL has been found to predict post-operative QOL, with continued declines in physical, social, and psychological states and slower recovery $(12,13)$. Factors that provoke the most fear in resectable NSCLC patients are not surgical risks of perioperative morbidity or mortality, but the physical and mental handicaps that hinder recovery postoperatively (14, 15). Common disease and treatment-related symptoms include dyspnea, cough, fatigue, pain, lack of appetite, and insomnia (16). The average number of symptoms per patient in NSCLC has been reported to be around 14 with 2.3 symptoms rated as severe (17). 
In a systematic review of symptoms in lung cancer, Cooley concluded that patients with lung cancer experienced multiple symptoms that differed across illness trajectories and treatments (16). In early stage NSCLC where surgical interventions are the primary treatment, postoperative symptoms include pain and dyspnea (3). Post-thoracotomy pain syndrome is defined as an aching or burning sensation that persists or recurs along the thoracotomy scar at least 2 months postoperatively, and neuropathic symptoms such as paresthesia-dysesthesia and hypoesthesia are reported in $69 \%$ and $40 \%$ of patients, respectively $(18,19)$. Immediately following a thoracotomy, $90 \%$ of patients report varying degrees of pain (20). The incidence of chronic post-thoracotomy pain is estimated to be 26$67 \%$ (20). Predictors of CPTP includes severe acute post-operative pain, high consumption of analgesics postoperatively, female gender, the extent of surgery, and psychological distress $(21,22)$.

Respiratory symptoms such as cough, dyspnea, wheeze, and hemoptysis are common in NSCLC, occurring in 40 to $85 \%$ of patients (23). These symptoms may be present at diagnosis or as a direct result of treatment, and prevalence is dependent on tumor type, disease stage, gender, age, and living situations $(24,25)$. Dales and colleagues followed NSCLC patients after thoracic surgery and found that dyspnea and QOL deteriorated up to 3 months postoperatively, but returned to baseline at 9 months (26). In a study exploring dyspnea and QOL in both early and late stage NSCLC patients $(n=120)$, Smith and colleagues found that advanced disease was not correlated with dyspnea. This finding suggests that early stage NSCLC patients who are most likely to be cured may also be faced with debilitating breathlessness that results in poor QOL during survivorship $(27,28)$. In one large prospective cohort study of 939 stage III or IV non-small cell lung cancer patients hospitalized at five teaching hospitals in the U.S., severe dyspnea was recorded in $32 \%$ of patients, and in $90 \%$ of patients near death (29).

The psychological implications of lung cancer have been documented extensively in the literature. A number of studies have documented the presence of depression among lung cancer patients, with an incidence rate of 15 to $44 \%$ in newly diagnosed NSCLC patients (30). Studies have shown that the 1, 2, and 3-month prevalence of depression in NSCLC patients after curative resection was $9.0 \%, 9.4 \%$, and $5.8 \%$, respectively (31). The prevalence of psychological distress is the highest among lung cancer patients compared to solid tumors (19). Factors that are associated with psychological distress include symptoms such as pain, poor performance, age, social support, physician support, and marital status (19). Faller \& Bulzebruck studied coping and survival in 103 lung cancer patients using a 10-year follow-up. Coping was assessed before treatment by using both self-reports and interviewer ratings. Findings suggest that self-reported depressive coping style was linked with shorter survival, and active coping style was linked with longer survival (32). Maliski and colleagues interviewed 29 lung cancer survivors (>10 yrs.) and identified five key themes including existential issues, health and self-care, physical ability, adjustment and support (33).

Research has shown that social support is associated with distress among cancer patients and is positively related to QOL $(34,35)$. Walker and colleagues found that the type of social support available to NSCLC patients predicted more adaptive coping in early stage disease $(\mathrm{n}=119)$ (36). A more assisting and cooperative support that leaves responsibilities and choices to the patient was associated with adaptive coping, while support that entails others taking responsibility for tasks and telling the patient what to do was associated with less adaptive coping (36). Worries about the illness, family, and the future relating to the illness are the most common psychosocial concerns (37). Hill and colleagues reported that less than half of NSCLC patient's concerns (43\%) were discussed by providers (37). Patients' 
psychosocial symptoms were more worrisome than physical symptoms, and psychosocial concerns were least likely to have been dealt with effectively (37).

Diagnosis of a life-threatening disease such as NSCLC can cause enormous spiritual distress. Finding meaning in illness has shown to positively affect QOL. A cross-sectional study conducted by Downe-Wamboldt and colleagues documented that overall QOL in NSCLC patients is predicted most by meaning of illness, specifically, the illness being perceived as manageable (38). In a study conducted among 60 NSCLC patients, Meraviglia found that people who reported more meaning in life had better psychological well-being. Furthermore, as the level of meaning in life increased, symptom distress decreased among the study participants (39). Finally, Sarna and colleagues examined the relationship between meaning of illness and QOL in women with NSCLC $(n=217)$. Findings suggest that depressed mood, negative conceptualizations of meaning of illness, and younger age explained 37\% of the variance of global QOL and were correlated with poorer QOL (40). In this study, more than a third of patients associated lung cancer with negative meaning (40).

\section{Palliative Symptom Management in Lung Cancer}

Given the multitude of symptoms patients can experience, alleviating discomfort often requires several treatment modalities to reach an acceptable goal of palliation. With respect to decrements in quality of life related specifically to the tumor itself, the general assault on health by lung cancer can be broadly separated into four categories of clinical problems: those caused by the primary tumor, those caused by metastases, those caused by treatment and finally those caused by paraneoplastic syndromes (41). In addition to problems attributable to the diagnosis of lung cancer, patients also often carry the burden of significant comorbid disease. Because the average age of presentation of lung cancer is 71 (42), a sizable percentage of patients with lung cancer will have pre-existing disease, both related and unrelated to tobacco products. Such tobacco-related diseases include cerebrovascular disease, coronary vascular disease, peripheral vascular disease, heart failure, aortic aneurysm and chronic obstructive lung disease. Despite the presence of these multiple comorbid diseases, the great majority of patients with lung cancer die of the lung cancer rather than the comorbid diseases, even when lung cancer presents in early stage.

Symptom management begins with a conversation between provider and patient, taking time to assess the patient's symptoms and educate the patient and family about possible treatment options. Clinicians should evaluate for potentially correctable causes of discomfort, and proceed with non-interventional symptom management if no cause can be identified (41). An awareness of the multiple treatment modalities available for palliation of symptoms related to lung cancer can aid the clinician in obtaining timely relief for the patient, who may have very little time remaining.

\section{Palliative Surgical Options}

The most common clinical situations in lung cancer patients that may benefit from invasive interventions include airway obstruction, hemoptysis, pleural or pericardial effusions, and brain or bone metastases. Worsening symptoms of dyspnea, hemoptysis and stridor warrant prompt bronchoscopic evaluation for airway obstruction. Airway obstruction can be inside the airway, within the airway wall, or extrinsically compressing the airway $(43,44)$. Palliative bronchoscopy with the goal of alleviating symptoms can be highly effective. Bronchoscopic options for treatment include short-term endotracheal intubation, tumor debulking, balloon dilation, laser therapy, electrocautery, cryotherapy, photodynamic therapy, argon plasma coagulation and airway stent placement (45). Airway obstruction can be endobronchial or extrinsic compression. When malignant central airway obstruction resulted in respiratory failure, urgent therapeutic bronchoscopy allowed 52\% of patients to 
come off the ventilator in one study (46). Balloon dilation is best used in conjunction with stent placement, and works best when small areas are stenosed (47). Laser debridement and electrocautery are only effective for intraluminal lesions, but can result in immediate relief of dyspnea in $55-90 \%$ of patients $(48,49)$. Cryotherapy and photodynamic therapy are also highly effective in relieving symptoms due to intraluminal airway obstruction, but require repeat treatment sessions with slow symptom relief (50).

Airway stents can be used for both intrinsic and extrinsic compressing lesions, and can be used in conjunction with other techniques including balloon dilation and laser debridement. The only true contraindication to stent placement is external airway compression by a vessel, as this can result in high rates of erosion, hemorrhage and death (51). Airway stents are also sometimes considered for palliative management of tracheoesophageal fistulas. Tracheoesophageal fistulas carry significant symptom burden for patients (i.e. aspiration, pneumonitis), along with inability to tolerate oral intake and marked reduced survival of 1-7 weeks (41). Aggressive interventions such as attempts at surgical repair or resection should be avoided, and stenting of both trachea and esophagus has yielded only modest benefit in limited trials (52-55). One small study of 24 patients showed that invasive treatment of endobronchial obstruction resulted in improved airway diameter in all patients and improved dyspnea in $85 \%$ of patients, but failed to show a significant improvement in quality of life scores (56).

Massive hemoptysis can be very distressing to patients, families and physicians, and prompt bronchoscopic evaluation for possible palliative therapy can be of benefit in some cases. Hemoptysis is a second clinical scenario in which invasive procedures may palliate symptoms of lung cancer. While physicians often define massive hemoptysis warranting intervention as greater than $200 \mathrm{cc}$ in twenty four hours, patients often consider small amounts of hemoptysis very concerning (57). Otherwise healthy persons presenting with hemoptysis are candidates for open lung surgery; however, lung cancer patients with hemoptysis often have advanced disease which makes them poor surgical candidates, and thus may benefit from less aggressive interventions. Therapeutic bronchoscopy with balloon tamponade and infusion of vasoactive agents such as epinephrine may be successful as a temporizing measure (58-62). If the area of bleeding can be directly visualized, bronchoscopic techniques such as Nd-YAG laser coagulation or electrocautery can also be used, with reported response rates of 60-100\% (63-65). Bronchial angiography with bronchial artery embolization can sometimes control hemoptysis.

Malignant pleural and pericardial effusions are a third common cause of dyspnea in lung cancer patients that can also be treated with palliative interventional procedures. When a pleural effusion is found in a lung cancer patient presenting with dyspnea, a diagnostic thoracentesis should first be done. The initial thoracentesis helps to determine if drainage relieves the patient's dyspnea and allows the lung to fully re-expand. For those with malignant pleural effusions and symptomatic improvement after thoracentesis, the recommended therapeutic options include serial thoracenteses, chest tube drainage with bedside chemical pleurodesis, surgical pleurodesis or pleural drain catheter placement.

Repeat thoracentesis is recommended in patients with very short life expectancy, as malignant pleural effusions recur in nearly $100 \%$ of patients within one month of initial drainage (40). Chemical pleurodesis carries a 50-95\% success rate, and appears to be most successful when performed using talc, according to a recent Cochran Review (66). Chemical pleurodesis can be done at the bedside but requires chest tube placement and a prolonged hospital stay; it can also occasionally be painful and cause pneumonitis in $4-8 \%$ of patients (67). Surgical pleurodesis is slightly more successful with a $75-100 \%$ success rate (41), but many advanced lung cancer patients are unlikely to be fit surgical candidates. Chemical 
pleurodesis require an expanded lung for success, and in patients who have rapidly accumulating effusions with trapped lung, these techniques are more likely to fail.

Tunneled pleural catheters have been recommended as first line for malignant pleural effusions, since they can be done as an outpatient, require only local anesthesia, and have high success rates of 85-95\%. In 1999 Putnam et al conducted a trial that lead to FDA approval of the Pleur $\mathrm{X}^{\mathrm{TM}}$ catheter, showing that pleurodesis with doxycycline had an average hospital stay of 6.5 days, while tunneled pleurX catheter placement required only 1 day (68).

In a recent paper advocating for tunneled pleural catheter placement as first line treatment of malignant pleural effusions, Tremblay et al wrote, "the current authors estimate that 1 week in the hospital represents $5 \%$ of a patient's remaining life expectancy, time that may be more beneficial spent at home with family and friends."(69) Recent cost-effectiveness analysis showed that tunneled pleural catheters became more cost effective when the life expectancy was six weeks or less (70). The study did not account for physician inpatient fees in the pleurodesis group and assumed three nursing visits per week were needed for the indwelling catheter group; given that the patient and family can easily be taught to care for the catheter and physician fees can be costly, the cost benefit of tunneled catheters is probably more pronounced than stated.

A review of 231 catheters placed for malignant pleural effusions showed a low infection rate of $2.2 \%$, usually limited to local cellulitis, and confirmed a high effectiveness rate, with $52 / 52$ catheters placed for lung cancer still in place and functional at the time of death (67). In summary, malignant pleural effusions are a treatable cause of dyspnea in lung cancer patients, and the selection of treatment method should be based on minimizing patient burden while maximizing symptom improvement and QOL.

Superior vena cava (SVC) syndrome occurs in $10 \%$ of patients with lung cancer involving the right hilum (71). Obstruction leads to a characteristic syndrome, with formation of collateral veins over the upper chest, facial swelling made worse with recumbency, headache, increased cerebral venous pressure, and in severe cases, blindness and coma. Palliation of these symptoms can often be achieved with a combination of chemotherapy and radiation therapy for non-small cell lung cancers.

Surgical palliation with bypass of the cava has been uncommonly performed in highly selected circumstances, but more recently endovascular stent placement by interventional radiologists has had increased success at alleviating symptoms. Case series report success rates of 94-95\% following stent placement, and many authors advocate stent placement as the initial treatment for immediate symptom relief with fewer complication (72-84).

Although surgery is the only curative treatment approach for lung cancer, the surgeon and interventional radiologist should be considered members of the extended team for the palliation of lung cancer symptoms. .

\section{Palliative Pharmacologic Options}

Medications are invariably used in the management of pain and dyspnea in lung cancer patients. Effective pain management may not mean complete pain relief, but more likely a significant alleviation in the patient's pain by at least 33-50\% (85-87). Pain medications should be administered in accordance with the National Comprehensive Cancer Network (NCCN) Pain Guidelines (88), beginning with non-opioids such as NSAIDS and acetaminophen, and continuing with the addition of opioids and adjuvants as needed. When opioids are administered, constipation should be prophylaxed against and continuously monitored. For neuropathic pain, adjuvants to analgesics such as anticonvulsants and tricyclic antidepressants can be very helpful. Steroids can aid in relief of symptoms caused 
by edema caused by spinal and intracranial metastases, while bisphosphonates can reduce pain related caused by bony metastases (89). The medication regimen should be kept as simple as possible to avoid further side effect and cost burden. The oral route of administration is preferred. When this is not possible, rectal or transdermal delivery is often feasible. For parenterally administered medication, the intravenous or subcutaneous routes should be used. Intramuscular administration has the disadvantages of increased pain with administration and unpredictable absorption. Inhaled administration of opioids is not recommended. (90).

Dyspnea in the setting of lung cancer can be attributed to five causes: direct involvement of lung tissue by cancer, indirect respiratory complications related to the cancer (postobstructive pneumonia and pleural effusions), treatment related complications (fibrosis secondary to chemotherapy or radiation), respiratory coomorbidities (pulmonary embolism) and other comorbid conditions (COPD, malnutrition and prior lung resection) (41). Pharmacologic management, options include bronchodilators, corticosteroids, anxiolytics, antidepressants, opiods and oxygen. A metaanaylsis of 18 randomized controlled trials confirmed that opioids are successful in relieving dyspnea (91). Because many lung cancer patients also have COPD, optimizing COPD treatment can be beneficial in relieving dyspnea. A prospective study of 100 terminally ill cancer patients, 49 of whom had lung cancer, showed that correctable causes of dyspnea included bronchospasm in $52 \%$ of patients and hypoxia in $40 \%$ of patients (92). Inhaled bronchodilators can assist with management of bronchospasm, while supplemental oxygen can treat dyspnea related hypoxia. There is some debate as to whether oxygen can also alleviate dyspnea in nonhypoxemic patients; for the advanced lung cancer population, oxygen prescription should be considered for all dyspneic patients regardless of oxygenation status, as it may improve exercise tolerance (93), and should not be delayed awaiting painful serial blood gases to confirm hypoxemic status.

Cough is a complaint seen in the initial presentations of $>65 \%$ of patients with lung cancer (94). In addition to treatment for correctable causes of cough, pharmacologic therapies that may be of benefit include cough suppressants, bronchodilators and opioids. Codeine is a popular and effective choice of opioid for suppressing this symptom. . Medical management of comorbid conditions contributing to cough such as COPD, gastroesophageal reflux and congestive heart failure can also be of benefit (95).

When death is imminent, oral and respiratory secretions become salient symptoms. . It is important to separate the nursing concerns of frequent suctioning, the family concerns of chest crackles, and the true symptoms of dyspnea or cough sensed by the patient. While opioids are the most successful agents for management of dyspnea, anticholinergic agents such as scopolamine and glycopyrrolate are preferred for control of copious secretions. . Symptoms such as pain and dyspnea that do not respond to initial therapy should prompt referral to palliative care and pain management specialists, from the time of presentation until the last days of life. .

\section{Palliative Chemotherapy}

Palliative chemotherapy may increase survival, and in some cases can improve pain and other symptoms (96-100). Palliative chemotherapy means chemotherapy given primarily for rapid relief of symptoms, not non-curative chemotherapy. Dyspnea related to pulmonary parenchymal toxicity from chemotherapy should be managed with discontinuation of the chemotherapeutic regimen and institution of steroids. This is a delicate balance in using chemotherapy to the full extent possible to relieve symptoms and reverse the underlying 
disease while also monitoring closely to determine when the chemotherapy may be adding to symptom burden and thus should be discontinued (101).

\section{Palliative Radiation}

Palliative radiation therapy can be used throughout the course of lung cancer: prior to surgery, along with chemotherapy, or as an independent treatment modality. Radiation therapy can be used as primary treatment of a lung cancer in settings where surgery is not indicated, because of location of tumor, advanced stage, comorbidities, or patient preference. Radiation therapy can be of palliative benefit to alleviate pain and neurologic deficits from brain and spinal metastases, relieve pain from bone metastases, and prevention of impending pathologic fracture. . Finally, radiation can also be given via interventional bronchoscopy as intraluminal brachytherapy to help control hemoptysis and airway obstruction by central tumors.

Radiation therapy has a wide spectrum of complications, depending on site, dose, method of dosing, and co-morbid conditions. . Although it is very uncommon for patients to die as a complication of radiation therapy, radiation pneumonitis can cause cough, shortness of breath and even death in a small percentage of patients. Spontaneous rib fractures can occur following a radiation treatment of the chest. Radiation-induced mucositis, esophagitis and skin changes are common complications, and radiation therapy effect on the heart and lung can combine with loss of function secondary to comorbid conditions and lung resection to impair cardiorespiratory function (102).

\section{Other Palliative Management Options}

The broad term of "supportive care" for patients with advanced lung cancer can include a variety of medical, psychological and alternative therapies, all of which can aid in the palliation of symptoms. One medical example would be the use of blood transfusions, which can alleviate fatigue and dyspnea associated with anemia, as well as improve quality of life (103). Interventions such as guided imagery, breathing techniques, educational tools can have a positive impact on common psychologic symptoms such as anxiety and depression that undermine quality of life. Finally, the involvement of social and spiritual support for patients and families cannot be underestimated, and can certainly impact physical symptoms, as well as overall quality of life. The task of integrating palliative surgical, medical and psychosocial care for the management of a patient with advanced lung cancer requires an interdisciplinary team, with all members of the team focused on how best to provide relief of suffering and the best quality of life possible for the patient's remaining years, days or hours.

\section{A Model for Integrating Palliative Care in Lung Cancer}

Figure 2 provides details on a model to improve palliative care for patients with lung cancer and their family caregivers. This model was developed based on extensive pilot work by the authors $(104,105)$. In our interdisciplinary palliative care model, a comprehensive assessment of patient and family caregivers' QOL concerns prior to treatment initiation begins this process of care. QOL assessment is focused on four domains: physical, psychological, social, and spiritual well-being. Following the comprehensive QOL assessment, an interdisciplinary care team meeting is scheduled and initiated. The team should include the patient's treating physician(s), RNs involved in patient care, as well as supportive care experts such as social workers, psychologists, spiritual counselors, pulmonary rehabilitation specialists, case managers, pain specialists, and dietitians. Together as an interdisciplinary team, the patient's QOL assessment, which includes physical, psychological, social, and spiritual dimensions, will be discussed, and a care plan will be 
produced to address each of the issues. Nursing coordination of care will be initiated based on the recommendations of the team, and includes patient/caregiver education, support from the team members, and referrals to supportive care services. Patient and family caregiver outcomes to be measured should include QOL, functional status, support services utilization, distress, resource utilization, and family caregiver self-care, burden, and skills preparedness.

Initial pilot studies and the development of the model at the City of Hope led to the design of a five-year program project funded by the National Cancer Institute to test the effectiveness of the interdisciplinary palliative care model to improve care for patients with lung cancer and their family caregivers. Consistent with the recommendations of the Institute of Medicine Report on palliative care (106), we believe that palliative care, including symptom management and attention to QOL concerns of patients and families, should be addressed throughout the trajectory of lung cancer. Three simultaneous projects are included within the program project. Project 1 is Early Stage Lung Cancer, and provides a model of integrating palliative care throughout the trajectory of disease. Project 2 focuses on Late Stage Lung Cancer, a population that has decreased survival and high QOL and symptom concerns. Project 3 focuses on Family Caregivers of patients with lung cancer.

\section{Conclusions}

Lung cancer continues to be the 2nd most common cancer in the United States with over 157,000 patients expected to die from the disease this year (1). Advancements in the surgical and medical treatment of lung cancer have resulted in more favorable short-term survival outcomes. Treatment, however, can be complex, and long-term survival with the most current, cutting-edge technologies remains elusive. After initial treatment, lung cancer requires continued surveillance and follow-up for long-term side effects and possible recurrence. The integration of quality palliative care into routine clinical care of patients with lung cancer following surgical intervention is essential in preserving function and optimizing QOL through survivorship. An interdisciplinary palliative care model can effectively link patients to the appropriate supportive care services in a timely fashion.

\section{References}

1. Jemal A, Siegel R, Xu J, Ward E. Cancer Statistics, 2010. CA: a cancer journal for clinicians. Jul 7.2010 2010:caac.20073.

2. Scott WJ, Howington J, Feigenberg S, Movsas B, Pisters K. Treatment of non-small cell lung cancer stage I and stage II: ACCP evidence-based clinical practice guidelines (2nd edition). Chest. Sep; 2007 132(3 Suppl):234S-242S. [PubMed: 17873171]

3. Spiro SG, Gould MK, Colice GL. Initial evaluation of the patient with lung cancer: symptoms, signs, laboratory tests, and paraneoplastic syndromes: ACCP evidenced-based clinical practice guidelines (2nd edition). Chest. Sep; 2007 132(3 Suppl):149S-160S. [PubMed: 17873166]

4. Kenny PM, King MT, Viney RC, et al. Quality of life and survival in the 2 years after surgery for non small-cell lung cancer. J Clin Oncol. Jan 10; 2008 26(2):233-241. [PubMed: 18086802]

5. National Consensus Project. [Accessed July 7, 2010.] Clinical Practice Guidelines for Quality Palliative Care. 2009. www.nationalconsensusproject.org

6. Temel JS, Greer JA, Muzikansky A, et al. Early palliative care for patients with metastatic nonsmall-cell lung cancer. The New England journal of medicine. Aug 19; 2010 363(8):733-742. [PubMed: 20818875]

7. Balduyck B, Hendriks J, Lauwers P, Van Schil P. Quality of life evolution after lung cancer surgery: a prospective study in 100 patients. Lung Cancer. Jun; 2007 56(3):423-431. [PubMed: 17306905]

8. Brunelli A, Socci L, Refai M, Salati M, Xiume F, Sabbatini A. Quality of life before and after major lung resection for lung cancer: a prospective follow-up analysis. Ann Thorac Surg. Aug; 2007 84(2):410-416. [PubMed: 17643607] 
9. Paull DE, Thomas ML, Meade GE, et al. Determinants of quality of life in patients following pulmonary resection for lung cancer. American journal of surgery. Nov; 2006 192(5):565-571. [PubMed: 17071185]

10. Balduyck B, Hendriks J, Lauwers P, Nia PS, Van Schil P. Quality of life evolution after lung cancer surgery in septuagenarians: a prospective study. European Journal of Cardio-Thoracic Surgery. 2009; 35(6):1070-1075. [PubMed: 19286388]

11. Handy JR Jr, Child AI, Grunkemeier GL, et al. Hospital readmission after pulmonary resection: prevalence, patterns, and predisposing characteristics. Ann Thorac Surg. Dec; 2001 72(6):18551859. discussion 1859-1860. [PubMed: 11789760]

12. Leo F, Scanagatta P, Vannucci F, Brambilla D, Radice D, Spaggiari L. Impaired quality of life after pneumonectomy: Who is at risk? The Journal of Thoracic and Cardiovascular Surgery. 2010; 139(1):49-52. [PubMed: 19660279]

13. Sarna L, Padilla G, Holmes C, Tashkin D, Brecht ML, Evangelista L. Quality of life of long-term survivors of non-small-cell lung cancer. J Clin Oncol. Jul 1; 2002 20(13):2920-2929. [PubMed: 12089220]

14. Cykert S, Kissling G, Hansen CJ. Patient preferences regarding possible outcomes of lung resection: what outcomes should preoperative evaluations target? Chest. Jun; 2000 117(6):15511559. [PubMed: 10858382]

15. Rocco G, Vaughan R. Outcome of lung surgery: what patients don't like. Chest. Jun; 2000 117(6): 1531-1532. [PubMed: 10858375]

16. Cooley ME. Symptoms in adults with lung cancer. A systematic research review. J Pain Symptom Manage. Feb; 2000 19(2):137-153. [PubMed: 10699541]

17. Evangelista LS, Sarna L, Brecht ML, Padilla G, Chen J. Health perceptions and risk behaviors of lung cancer survivors. Heart Lung. Mar-Apr;2003 32(2):131-139. [PubMed: 12734536]

18. Gotoda Y, Kambara N, Sakai T, Kishi Y, Kodama K, Koyama T. The morbidity, time course and predictive factors for persistent post-thoracotomy pain. European journal of pain (London, England). 2001; 5(1):89-96.

19. Wilkie D, Berry D, Cain K, et al. Effects of Coaching Patients With Lung Cancer to Report Cancer Pain. West J Nurs Res. Feb 1; 2010 32(1):23-46. [PubMed: 20164474]

20. Pluijms WA, Steegers MA, Verhagen AF, Scheffer GJ, Wilder-Smith OH. Chronic postthoracotomy pain: a retrospective study. Acta anaesthesiologica Scandinavica. Aug; 2006 50(7): 804-808. [PubMed: 16879462]

21. Perkins FM, Kehlet H. Chronic pain as an outcome of surgery. A review of predictive factors. Anesthesiology. Oct; 2000 93(4):1123-1133. [PubMed: 11020770]

22. Rogers ML, Duffy JP. Surgical aspects of chronic post-thoracotomy pain. Eur J Cardiothorac Surg. Dec; 2000 18(6):711-716. [PubMed: 11113680]

23. Schulte T, Schniewind B, Dohrmann P, Küchler T, Kurdow R. The Extent of Lung Parenchyma Resection Significantly Impacts Long-Term Quality of Life in Patients With Non-Small Cell Lung Cancer. Chest. Feb; 2009 135(2):322-329. [PubMed: 18689576]

24. Chernecky C, Sarna L, Waller JL, Brecht ML. Assessing coughing and wheezing in lung cancer: a pilot study. Oncology nursing forum. Nov; 2004 31(6):1095-1101. [PubMed: 15547632]

25. Smith EL, Hann DM, Ahles TA, et al. Dyspnea, anxiety, body consciousness, and quality of life in patients with lung cancer. J Pain Symptom Manage. Apr; 2001 21(4):323-329. [PubMed: 11312047]

26. Dales RE, Belanger R, Shamji FM, Leech J, Crepeau A, Sachs HJ. Quality-of-life following thoracotomy for lung cancer. Journal of clinical epidemiology. Dec; 1994 47(12):1443-1449. [PubMed: 7730853]

27. Sarna L, Cooley ME, Brown JK, Chernecky C, Elashoff D, Kotlerman J. Symptom Severity 1 to 4 Months After Thoracotomy for Lung Cancer. Am J Crit Care. Sep 1; 2008 17(5):455-467. [PubMed: 18776002]

28. Sarna L, Evangelista L, Tashkin D, et al. Impact of respiratory symptoms and pulmonary function on quality of life of long-term survivors of non-small cell lung cancer. Chest. Feb; 2004 125(2): 439-445. [PubMed: 14769722] 
29. Claessens MT, Lynn J, Zhong Z, et al. Dying with lung cancer or chronic obstructive pulmonary disease: insights from SUPPORT. Study to Understand Prognoses and Preferences for Outcomes and Risks of Treatments. Journal of the American Geriatrics Society. May; $200048(5$ Suppl):S146-153. [PubMed: 10809468]

30. Hopwood P, Stephens RJ. Depression in patients with lung cancer: prevalence and risk factors derived from quality-of-life data. J Clin Oncol. Feb; 2000 18(4):893-903. [PubMed: 10673533]

31. Uchitomi Y, Mikami I, Kugaya A, et al. Depression after successful treatment for nonsmall cell lung carcinoma. Cancer. Sep 1; 2000 89(5):1172-1179. [PubMed: 10964348]

32. Faller H, Bulzebruck H. Coping and survival in lung cancer: a 10-year follow-up. The American journal of psychiatry. Dec; 2002 159(12):2105-2107. [PubMed: 12450966]

33. Maliski SL, Sarna L, Evangelista L, Padilla G. The aftermath of lung cancer: balancing the good and bad. Cancer Nurs. Jun; 2003 26(3):237-244. [PubMed: 12832957]

34. Hann D, Baker F, Denniston M, et al. The influence of social support on depressive symptoms in cancer patients: age and gender differences. Journal of psychosomatic research. May; 2002 52(5): 279-283. [PubMed: 12023124]

35. Kuo TT, Ma FC. Symptom distresses and coping strategies in patients with non-small cell lung cancer. Cancer Nurs. Aug; 2002 25(4):309-317. [PubMed: 12181499]

36. Walker MS, Zona DM, Fisher EB. Depressive symptoms after lung cancer surgery: Their relation to coping style and social support. Psychooncology. Aug; 2006 15(8):684-693. [PubMed: 16302291]

37. Hill KM, Amir Z, Muers MF, Connolly CK, Round CE. Do newly diagnosed lung cancer patients feel their concerns are being met? European journal of cancer care. Mar; 2003 12(1):35-45. [PubMed: 12641555]

38. Downe-Wamboldt B, Butler L, Coulter L. The relationship between meaning of illness, social support, coping strategies, and quality of life for lung cancer patients and their family members. Cancer Nurs. Mar-Apr;2006 29(2):111-119. [PubMed: 16565620]

39. Meraviglia MG. The effects of spirituality on well-being of people with lung cancer. Oncology nursing forum. Jan-Feb;2004 31(1):89-94. [PubMed: 14722592]

40. Sarna L, Brown JK, Cooley ME, et al. Quality of life and meaning of illness of women with lung cancer. Oncology nursing forum. Jan; 2005 32(1):E9-19. [PubMed: 15660139]

41. Kvale PA, Selecky PA, Prakash UB. Palliative care in lung cancer: ACCP evidence-based clinical practice guidelines (2nd edition). Chest. Sep; 2007 132(3 Suppl):368S-403S. [PubMed: 17873181]

42. Jemal A, Thun MJ, Ries LA, et al. Annual report to the nation on the status of cancer, 1975-2005, featuring trends in lung cancer, tobacco use, and tobacco control. Journal of the National Cancer Institute. Dec 3; 2008 100(23):1672-1694. [PubMed: 19033571]

43. Diacon AH, Bolliger CT. Functional evaluation before and after interventional bronchoscopy in patients with malignant central airway obstruction. Monaldi Arch Chest Dis. Feb; 2001 56(1):6773. [PubMed: 11407214]

44. Ernst A, Feller-Kopman D, Becker HD, Mehta AC. Central airway obstruction. Am J Respir Crit Care Med. Jun 15; 2004 169(12):1278-1297. [PubMed: 15187010]

45. Prakash, UB. Bronchoscopy. In: Murray, J.; Nadel, J., editors. Murray and Nadel's textbook of respiratory medicine. Philadelphia: Saunders; 2005. p. 1617-1650.

46. Colt HG, Harrell JH. Therapeutic rigid bronchoscopy allows level of care changes in patients with acute respiratory failure from central airways obstruction. Chest. Jul; 1997 112(1):202-206. [PubMed: 9228377]

47. Ball JB, Delaney JC, Evans CC, Donnelly RJ, Hind CR. Endoscopic bougie and balloon dilatation of multiple bronchial stenoses: 10 year follow up. Thorax. Dec; 1991 46(12):933-935. [PubMed: 1792645]

48. Coulter TD, Mehta AC. The heat is on: impact of endobronchial electrosurgery on the need for NdYAG laser photoresection. Chest. Aug; 2000 118(2):516-521. [PubMed: 10936149]

49. Schumann C, Hetzel M, Babiak AJ, et al. Endobronchial tumor debulking with a flexible cryoprobe for immediate treatment of malignant stenosis. J Thorac Cardiovasc Surg. Apr; 2010 139(4):997-1000. [PubMed: 19716140] 
50. Moghissi K, Dixon K, Stringer M, Freeman T, Thorpe A, Brown S. The place of bronchoscopic photodynamic therapy in advanced unresectable lung cancer: experience of 100 cases. Eur J Cardiothorac Surg. Jan; 1999 15(1):1-6. [PubMed: 10077365]

51. Wood DE. Airway stenting. Chest Surg Clin N Am. Nov; 2001 11(4):841-860. [PubMed: 11780299]

52. Colt HG, Meric B, Dumon JF. Double stents for carcinoma of the esophagus invading the tracheobronchial tree. Gastrointest Endosc. Jul-Aug;1992 38(4):485-489. [PubMed: 1380932]

53. Freitag L, Tekolf E, Steveling H, Donovan TJ, Stamatis G. Management of malignant esophagotracheal fistulas with airway stenting and double stenting. Chest. Nov; 1996 110(5): 1155-1160. [PubMed: 8915213]

54. Shin JH, Song HY, Ko GY, Lim JO, Yoon HK, Sung KB. Esophagorespiratory fistula: long-term results of palliative treatment with covered expandable metallic stents in 61 patients. Radiology. Jul; 2004 232(1):252-259. [PubMed: 15166325]

55. van den Bongard HJ, Boot H, Baas P, Taal BG. The role of parallel stent insertion in patients with esophagorespiratory fistulas. Gastrointest Endosc. Jan; 2002 55(1):110-115. [PubMed: 11756930]

56. Amjadi K, Voduc N, Cruysberghs Y, et al. Impact of interventional bronchoscopy on quality of life in malignant airway obstruction. Respiration. 2008; 76(4):421-428. [PubMed: 18758153]

57. Corner J, Hopkinson J, Fitzsimmons D, Barclay S, Muers M. Is late diagnosis of lung cancer inevitable? Interview study of patients' recollections of symptoms before diagnosis. Thorax. Apr; 2005 60(4):314-319. [PubMed: 15790987]

58. Gottlieb LS, Hillberg R. Endobronchial tamponade therapy for intractable hemoptysis. Chest. Apr; 1975 67(4):482-483. [PubMed: 1122780]

59. Hiebert CA. Balloon catheter control of life-threatening hemoptysis. Chest. Sep; 1974 66(3):308309. [PubMed: 4422988]

60. Saw EC, Gottlieb LS, Yokoyama T, Lee BC. Flexible fiberoptic bronchoscopy and endobronchial tamponade in the management of massive hemoptysis. Chest. Nov; 1976 70(5):589-591. [PubMed: 975973]

61. Swersky RB, Chang JB, Wisoff BG, Gorvoy J. Endobronchial balloon tamponade of hemoptysis in patients with cystic fibrosis. Ann Thorac Surg. Mar; 1979 27(3):262-264. [PubMed: 378149]

62. Valipour A, Kreuzer A, Koller H, Koessler W, Burghuber OC. Bronchoscopy-guided topical hemostatic tamponade therapy for the management of life-threatening hemoptysis. Chest. Jun; 2005 127(6):2113-2118. [PubMed: 15947328]

63. Hetzel MR, Smith SG. Endoscopic palliation of tracheobronchial malignancies. Thorax. May; 1991 46(5):325-333. [PubMed: 1712516]

64. Morice RC, Ece T, Ece F, Keus L. Endobronchial argon plasma coagulation for treatment of hemoptysis and neoplastic airway obstruction. Chest. Mar; 2001 119(3):781-787. [PubMed: 11243957]

65. Jain PR, Dedhia HV, Lapp NL, Thompson AB, Frich JC Jr. Nd:YAG laser followed by radiation for treatment of malignant airway lesions. Lasers Surg Med. 1985; 5(1):47-53. [PubMed: 3920460]

66. Shaw P, Agarwal R. Pleurodesis for malignant pleural effusions. Cochrane database of systematic reviews (Online). 2006:1.

67. Warren WH, Kalimi R, Khodadadian LM, Kim AW. Management of malignant pleural effusions using the Pleur(x) catheter. Ann Thorac Surg. Mar; 2008 85(3):1049-1055. [PubMed: 18291195]

68. Putnam JB Jr, Light RW, Rodriguez RM, et al. A randomized comparison of indwelling pleural catheter and doxycycline pleurodesis in the management of malignant pleural effusions. Cancer. Nov 15; 1999 86(10):1992-1999. [PubMed: 10570423]

69. Tremblay A, Mason C, Michaud G. Use of tunnelled catheters for malignant pleural effusions in patients fit for pleurodesis. Eur Respir J. Oct; 2007 30(4):759-762. [PubMed: 17567670]

70. Olden AM, Holloway R. Treatment of malignant pleural effusion: PleuRx catheter or talc pleurodesis? A cost-effectiveness analysis. Journal of palliative medicine. Jan; 13(1):59-65. [PubMed: 19839739]

71. Baker GL, Barnes HJ. Superior vena cava syndrome: etiology, diagnosis, and treatment. Am J Crit Care. Jul; 1992 1(1):54-64. [PubMed: 1307879] 
72. Rowell NP, Gleeson FV. Steroids, radiotherapy, chemotherapy and stents for superior vena caval obstruction in carcinoma of the bronchus: a systematic review. Clin Oncol (R Coll Radiol). Oct; 2002 14(5):338-351. [PubMed: 12555872]

73. Bierdrager E, Lampmann LE, Lohle PN, et al. Endovascular stenting in neoplastic superior vena cava syndrome prior to chemotherapy or radiotherapy. Neth J Med. Jan; 2005 63(1):20-23. [PubMed: 15719848]

74. Chatziioannou A, Alexopoulos T, Mourikis D, et al. Stent therapy for malignant superior vena cava syndrome: should be first line therapy or simple adjunct to radiotherapy. Eur J Radiol. Sep; 2003 47(3):247-250. [PubMed: 12927670]

75. Courtheoux P, Alkofer B, Al Refai M, Gervais R, Le Rochais JP, Icard P. Stent placement in superior vena cava syndrome. Ann Thorac Surg. Jan; 2003 75(1):158-161. [PubMed: 12537210]

76. de Gregorio Ariza MA, Gamboa P, Gimeno MJ, et al. Percutaneous treatment of superior vena cava syndrome using metallic stents. Eur Radiol. Apr; 2003 13(4):853-862. [PubMed: 12664126]

77. Garcia Monaco R, Bertoni H, Pallota G, et al. Use of self-expanding vascular endoprostheses in superior vena cava syndrome. Eur J Cardiothorac Surg. Aug; 2003 24(2):208-211. [PubMed: 12895609]

78. Greillier L, Barlesi F, Doddoli C, et al. Vascular stenting for palliation of superior vena cava obstruction in non-small-cell lung cancer patients: a future 'standard' procedure? Respiration. Mar-Apr;2004 71(2):178-183. [PubMed: 15031575]

79. Kee ST, Kinoshita L, Razavi MK, Nyman UR, Semba CP, Dake MD. Superior vena cava syndrome: treatment with catheter-directed thrombolysis and endovascular stent placement. Radiology. Jan; 1998 206(1):187-193. [PubMed: 9423671]

80. Lanciego C, Chacon JL, Julian A, et al. Stenting as first option for endovascular treatment of malignant superior vena cava syndrome. AJR Am J Roentgenol. Sep; 2001 177(3):585-593. [PubMed: 11517051]

81. Lau KY, Tan LT, Wong WW, Lee AS. Brachiocephalic-superior vena cava metallic stenting in malignant superior vena cava obstruction. Ann Acad Med Singapore. Jul; 2003 32(4):461-465. [PubMed: 12968550]

82. Nicholson AA, Ettles DF, Arnold A, Greenstone M, Dyet JF. Treatment of malignant superior vena cava obstruction: metal stents or radiation therapy. J Vasc Interv Radiol. Sep-Oct;1997 8(5): 781-788. [PubMed: 9314368]

83. Tanigawa N, Sawada S, Mishima K, et al. Clinical outcome of stenting in superior vena cava syndrome associated with malignant tumors. Comparison with conventional treatment. Acta Radiol. Nov; 1998 39(6):669-674. [PubMed: 9817039]

84. Urruticoechea A, Mesia R, Dominguez J, et al. Treatment of malignant superior vena cava syndrome by endovascular stent insertion. Experience on 52 patients with lung cancer. Lung Cancer. Feb; 2004 43(2):209-214. [PubMed: 14739042]

85. Cepeda MS, Africano JM, Polo R, Alcala R, Carr DB. What decline in pain intensity is meaningful to patients with acute pain? Pain. Sep; 2003 105(1-2):151-157. [PubMed: 14499431]

86. Farrar JT, Berlin JA, Strom BL. Clinically important changes in acute pain outcome measures: a validation study. J Pain Symptom Manage. May; 2003 25(5):406-411. [PubMed: 12727037]

87. Jensen MP. The validity and reliability of pain measures in adults with cancer. J Pain. Feb; 2003 4(1):2-21. [PubMed: 14622723]

88. National Comprehensive Cancer Network. [Accessed August 9, 2010.] Adult Pain Guidelines. 2010. www.ncen.org

89. Paice, J. Pain at the end of life. In: Ferrell, B.; Coyle, N., editors. Oxford Textbook of Palliative Nursing. 3. New York: Oxford University Press; 2010. p. 161-186.

90. Dudgoen, D. Dyspnea, death rattle, and cough. In: Ferrell, B.; Coyle, N., editors. Oxford Textbook of Palliative Nursing. 3. New York: Oxford University Press; 2010. p. 303-320.

91. Jennings AL, Davies AN, Higgins JP, Gibbs JS, Broadley KE. A systematic review of the use of opioids in the management of dyspnoea. Thorax. Nov; 2002 57(11):939-944. [PubMed: 12403875]

92. Dudgeon DJ, Lertzman M. Dyspnea in the advanced cancer patient. J Pain Symptom Manage. Oct; 1998 16(4):212-219. [PubMed: 9803048] 
93. Emtner M, Porszasz J, Burns M, Somfay A, Casaburi R. Benefits of supplemental oxygen in exercise training in nonhypoxemic chronic obstructive pulmonary disease patients. Am J Respir Crit Care Med. Nov 1; 2003 168(9):1034-1042. [PubMed: 12869359]

94. Vaaler AK, Forrester JM, Lesar M, Edison M, Venzon D, Johnson BE. Obstructive atelectasis in patients with small cell lung cancer. Incidence and response to treatment. Chest. Jan; 1997 111(1): 115-120. [PubMed: 8996004]

95. Kvale PA. Chronic cough due to lung tumors: ACCP evidence-based clinical practice guidelines. Chest. Jan; 2006 129(1 Suppl):147S-153S. [PubMed: 16428704]

96. Macbeth F, Stephens R. Palliative treatment for advanced non-small cell lung cancer. Hematology/ oncology clinics of North America. Feb; 2004 18(1):115-130. [PubMed: 15005285]

97. Medley L, Cullen M. Best supportive care versus palliative chemotherapy in nonsmall-cell lung cancer. Current opinion in oncology. Jul; 2002 14(4):384-388. [PubMed: 12130920]

98. Plunkett TA, Chrystal KF, Harper PG. Quality of life and the treatment of advanced lung cancer. Clin Lung Cancer. Jul; 2003 5(1):28-32. [PubMed: 14596700]

99. Spiro SG, Rudd RM, Souhami RL, et al. Chemotherapy versus supportive care in advanced nonsmall cell lung cancer: improved survival without detriment to quality of life. Thorax. Oct; 2004 59(10):828-836. [PubMed: 15454647]

100. Thongprasert S, Sanguanmitra P, Juthapan W, Clinch J. Relationship between quality of life and clinical outcomes in advanced non-small cell lung cancer: best supportive care (BSC) versus BSC plus chemotherapy. Lung Cancer. Apr; 1999 24(1):17-24. [PubMed: 10403690]

101. Non-Small-Cell Lung Cancer Collaborative Group. Chemotherapy and supportive care versus supportive care alone for advanced non-small cell lung cancer. Cochrane database of systematic reviews (Online). 2010; (5)

102. National Comprehensive Cancer Network. [Accessed August 9, 2010.] Clinical Guidelines in Oncology: Non-Small-Cell Lung Cancer. 2010. www.nccn.org

103. Boyar M, Raftopoulos H. Supportive care in lung cancer. Hematology/oncology clinics of North America. Apr; 2005 19(2):369-387. vii. [PubMed: 15833411]

104. Borneman T, Koczywas M, Cristea M, Reckamp K, Sun V, Ferrell B. An interdisciplinary care approach for integration of palliative care in lung cancer. Clin Lung Cancer. Nov; 2008 9(6): 352-360. [PubMed: 19073518]

105. Podnos YD, Borneman TR, Koczywas M, Uman G, Ferrell BR. Symptom concerns and resource utilization in patients with lung cancer. Journal of palliative medicine. Aug; 2007 10(4):899-903. [PubMed: 17803411]

106. Institute of Medicine. Improving Palliative Care for Cancer. Washington, DC: National Academy Press; 2001. 


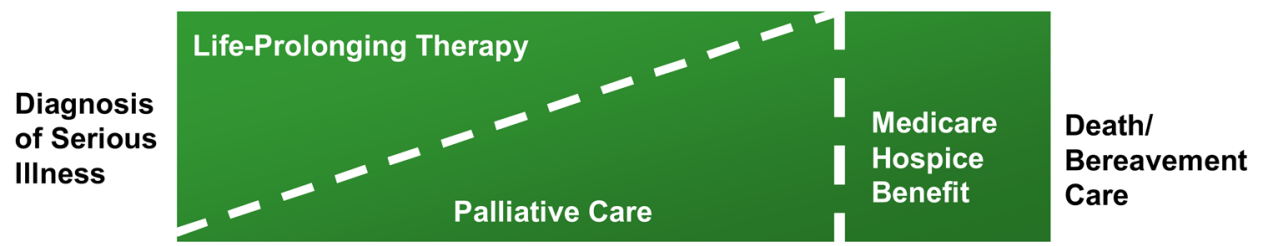

Figure 1.

How palliative care fits with the treatment of lung cancer. Palliative care begins at the time of diagnosis of a serious disease, continues throughout treatment, cure, or until death, and involves the family during the bereavement period. 


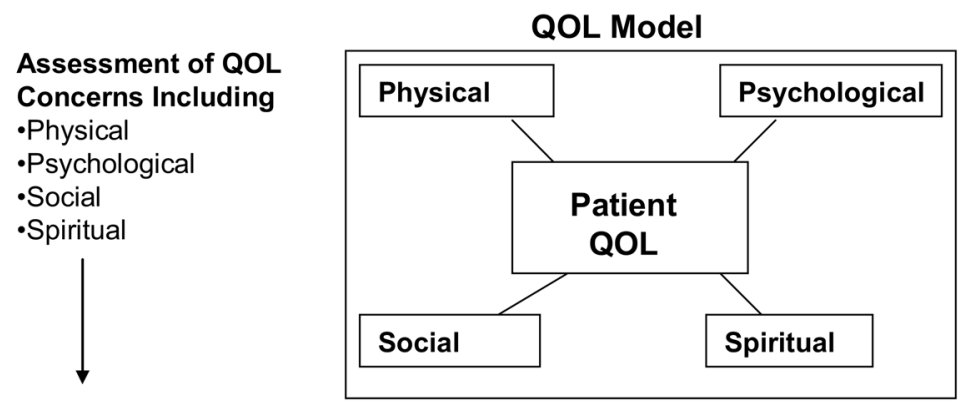

\section{PC Intervention}

Patient

-Pulmonary

Rehabilitation

-APN consultation

-Self Care

-Psychological Support

-Smoking Cessation

- Chaplaincy

- Transitions in Care

Interdisciplinary Team

Conference to plan care

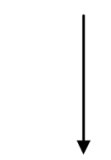

Nursing Coordination of Care Based on IDT

-4 Part Patient/Caregiver

Education

-IDT Support

-Phone Support

\section{- Social Work}

- Case Management

-Physical Symptom

Management

-Nutrition

-Rehab

Family Caregiver

-Physical Symptoms

- Psychological Concerns

-Self Care Plan

-Social Work

- Link to community

resources e.g., smoking,

financial

-Caregiver Information

-Spiritual Support
Outcomes

Patient

-QOL

*Physical

* Psychological

* Social

* Spiritual

-Function

- Use of Support Services

-Distress

- Resource Utilization

Family Caregiver

-QOL

* Physical

* Psychological

* Social

* Spiritual

- Use of Support Services

- Self Care

- Caregiver

Burden/Preparation

-Distress

Influencing Variables

Figure 2.

A Model of Care for Patients with Lung Cancer and Family Caregivers 